\title{
Carnivory and resource-based niche differentiation in anuran larvae: implications for food web and experimental ecology
}

\author{
LUIS SCHIESARI, EARL E. WERNER AND GEORGE W. KLING \\ Department of Ecology and Evolutionary Biology, The University of Michigan, Ann Arbor, MI, U.S.A.
}

\section{SUMMARY}

1. Food webs represent the paths of material and energy flow through organisms in an ecosystem. Anuran larvae are important components of pond food webs: they are abundant, consume large quantities of food and serve as prey for many organisms. However, there are very basic uncertainties about the feeding ecology of anuran larvae; for instance, as to which trophic level they belong and whether species differ in resource use. Because anuran larvae have been employed in model systems in experimental ecology for decades, these uncertainties could lead to misinterpretation of published experiments, or inadequate designs of experiments directed at general, conceptual issues in ecology.

2. Using ${ }^{13} \mathrm{C}$ and ${ }^{15} \mathrm{~N}$ stable isotope and gut content analyses of free-ranging and enclosed tadpoles of four ranid species (Lithobates sylvaticus, L. pipiens, L. clamitans, L. catesbeianus) in the food webs of six wetlands, we tested the following null hypotheses: (i) that anuran larvae are strict primary consumers; (ii) that they are non-selective feeders and therefore exhibit little feeding niche differentiation; (iii) that they are opportunistic consumers and (iv) that their diet remains unchanged through ontogeny.

3. All four species consumed and assimilated substantial amounts of animal food; bullfrog larvae, in particular, appear to be predatory. Significant feeding niche differentiation among species occurred with respect to the sources of carbon, consumption of animal matter and nutritional quality of food ingested. We further documented opportunistic feeding habits and ontogenetic shifts in diet.

4. Collectively, these studies revealed complex trophic relationships that might require a reconsideration of the role of anuran larvae in pond food webs, as well as a reinterpretation of results of previous studies employing anuran larvae in model experimental systems.

Keywords: anuran larvae, feeding ecology, food web, stable isotopes, wetland

Correspondence: Luis Schiesari, Department of Ecology and Evolutionary Biology, The University of Michigan, Ann Arbor, MI 48109-1048, U.S.A. E-mail: 1schiesa@usp.br

Present Address: Luis Schiesari, Environmental Management, School of Arts, Sciences and Humanities, University of São Paulo (EACH-USP), Av. Arlindo Bétio 1000, Parque Ecológico do Tietê, 03828-080, São Paulo-SP, Brazil.

\section{Introduction}

One of the central tenets of ecology is that species interactions can have large effects on the properties of communities such as diversity, stability and productivity. To examine the consequences of these interactions for community properties, ecologists often find it useful to conceptualize the community as a food web (e.g. Polis \& Winemiller, 1996). The direct 
consumer-resource interaction then forms the fundamental link in the food web, although the structure of the web also reveals that species interact indirectly with each other and many system properties are a function of the nature and strength of these indirect effects (reviewed in Schoener, 1993; Menge et al., 1994; Abrams et al., 1996; Polis \& Winemiller, 1996). Thus, our ability to assess the consequences of food web interactions hinges on a sound knowledge of the position and connections of a species in the web.

Anuran larvae are often key elements in the food webs of ponds and streams, where they can reach high densities and biomass, exhibit high per-capita consumption rates and serve as important prey for a number of other species. Moreover, anuran larvae have been widely employed for over three decades in model experimental systems to test conceptual hypotheses in community ecology (Wilbur, 1997; Werner, 1998). Nevertheless, there remains considerable uncertainty even about the basic feeding ecology of anuran larvae and therefore how they relate to other species in the food web. Anuran larvae have been traditionally regarded as microphagous, suspension-feeding herbivores and detritivores (Duellman \& Trueb, 1986; Altig, Whiles \& Taylor, 2007). However, observations of opportunistic oophagy, carnivory or necrophagy have led to recurrent questions concerning the actual sources of nutrition of tadpoles spanning over 100 years of herpetological literature (Boulenger, 1898; Savage, 1952; Wassersug, 1975; Duellman \& Trueb, 1986; Petranka \& Kennedy, 1999; and reviews in Alford, 1999; Hoff et al., 1999; Altig et al., 2007). Furthermore, anuran larvae are typically viewed as feeding unselectively (Farlowe, 1928; Heyer, 1973; Seale, 1980; but see Kupferberg, 1997) and therefore exhibiting little feeding niche differentiation and competing strongly. Because anuran larvae have been used in model experimental systems, misconceptions regarding the actual sources of their nutrition and trophic position can have potentially serious implications for our interpretations of this literature (as previously raised by Petranka \& Kennedy, 1999), and are likely to have contributed to debates on the realism of experimental outcomes in these model systems (e.g. Skelly \& Kiesecker, 2001; Chalcraft, Binckley \& Resetarits, 2005).

In this study, we test four null hypotheses regarding the feeding ecology of generalized anuran larvae that are key to understanding their position and role in food webs: (i) that they are strict primary consumers; (ii) that they are non-selective feeders and therefore exhibit little feeding niche differentiation; (iii) that they are opportunistic consumers and (iv) that their diet remains unchanged through ontogeny. We tested these hypotheses through a comparative study of the feeding ecology of four congeneric species of anurans, representing typical, morphologically generalized pond-dwelling larvae (sensu Duellman \& Trueb, 1986). We measured the ${ }^{13} \mathrm{C}$ and ${ }^{15} \mathrm{~N}$ isotopic signatures of these anuran larvae and other organisms in the food webs of six natural wetlands, and complemented these with analyses of tadpole foregut contents and their $\mathrm{C}: \mathrm{N}$ ratios. Stable isotope methodology permitted inferences on the sources and quality of nutrition, trophic level (TL) and intraspecific and interspecific feeding niche differentiation. Interspecific comparisons were further strengthened by conducting similar analyses on tadpoles transplanted in pairwise species combinations to replicated enclosures in the same wetlands. This experiment thus minimized effects of habitat heterogeneity, microhabitat segregation and variation in mean body mass in interspecific comparisons.

\section{Methods}

\section{Laboratory experiment of isotopic fractionation in tadpole tissues}

In order to calibrate estimates of tadpole TL, we conducted a laboratory experiment to measure the isotopic fractionation factors in wood frog (Lithobates sylvaticus LeConte, formerly Rana sylvatica) tadpole heart tissue relative to a constant food source. We analysed the heart because substantial protein turnover occurs in this tissue within the timescale of the experiments reported in this article (c. weeks), and therefore is likely to reflect short term dietary incorporation of ${ }^{15} \mathrm{~N}$ and ${ }^{13} \mathrm{C}$ (Guelinckx et al., 2007). Wood frog egg masses were collected in a pond near Independence Lake, Webster, Michigan, U.S.A., and hatched in the laboratory. On 27 April 2003, 10 tadpoles were placed in each of three 9.5-L containers filled with aged well water and fed a diet consisting exclusively of rabbit food (c. 16\% protein; Purina Mills, St Louis, MO, U.S.A.). Tadpoles were fed ad libitum twice a week and water replaced 
weekly. Samples of food and of developing tadpoles were frozen sequentially over 40 days and analysed for their isotopic composition $(0.32 \pm 0.08 \mathrm{mg}$ of sample analysed for tadpoles $790 \pm 93 \mathrm{mg}, n=4$ ). Isotopic fractionation was calculated as [mean tadpole $\delta^{13} \mathrm{C}$ (or $\delta^{15} \mathrm{~N}$ )]-[mean food $\delta^{13} \mathrm{C}$ (or $\delta^{15} \mathrm{~N}$ )] (see below).

\section{Field experiments and sampling}

(a) Study system. The study system comprised four species of congeneric larval frogs, the wood frog (L. sylvaticus; Frost, 2007), the leopard frog (Lithobates pipiens Schreber, formerly Rana pipiens), the green frog (Lithobates clamitans Latreille, formerly Rana clamitans) and the bullfrog (Lithobates catesbeianus Shaw, formerly Rana catesbeiana). This system offers a conservative test for investigating carnivory and complex trophic interactions because all four species represent typical, morphologically generalized pond-dwelling larvae, and are phylogenetically related (with L. catesbeianus and L. clamitans being members of the catesbeianus species group, having L. sylvaticus as sister group; and this clade having as sister group a large clade containing over 40 species including L. pipiens; Hillis \& Wilcox, 2005). These species differ in breeding phenology: wood and leopard frogs breed early in the spring and metamorphose that same summer. Bullfrogs and green frogs breed during the summer and usually overwinter as larvae at least once. All four species colonize productive, open-canopy ponds where planktonic and periphytic algae as well as macrophytes are abundant. Wood frogs, in addition, colonize the relatively unproductive closed-canopy ponds where aquatic primary producers are comparatively rare and decomposing leaf-litter is the most abundant basal resource (Skelly, Werner \& Cortwright, 1999; Schiesari, 2004, 2006).

Fieldwork was conducted in five natural waterbodies on the E.S. George Reserve (hereafter ESGR) of the University of Michigan near Pinckney, Michigan $\left(42^{\circ} 28^{\prime} \mathrm{N}, 84^{\circ} 00^{\prime} \mathrm{W}\right)$ (Southwest Woods Pond - henceforth SWW, West Woods Big - WWB, Fishhook Marsh - FH; Crane Pond - CR; Southwest Swamp - SWS), and one waterbody in Independence Lake County Park, Webster, Michigan, U.S.A. (Independence Marsh - IND). SWW and WWB are closed-canopy ponds and have abundant leaf-litter detritus, but comparatively little periphyton and macrophyte cov- er. The remaining ponds are open-canopy and contain abundant macrophyte and periphyton cover. Pond hydroperiods ranged from temporary to permanent (in rough order of hydroperiod: WWB, SWW, FH, IND, SWS and CR).

Field experiment. In order to test for feeding niche differentiation among these species, we experimentally transplanted anuran larvae into replicate enclosures in each waterbody. We conducted these experiments because (i) species do not always co-occur naturally at densities sufficient to allow adequate sampling and (ii) interspecific comparisons are more powerful when controlling for habitat selection and interspecific variation in body size.

Anuran larvae were raised from $>12$ egg masses for each species collected from a temporary pond near Pinckney (wood frogs), in IND (leopard frogs), and in ponds at the ESGR or at the Michigan DNR pond facility at Saline, Michigan (bullfrogs and green frogs). All tadpoles were reared in 300-L wading pools and fed rabbit food ad libitum until used in the experiments.

Experiments were conducted in four replicated enclosures in each of the six ponds (see Schiesari, 2004, 2006 for details). Enclosures were constructed of wooden frames $\left(1.50 \times 0.80 \times 1 \mathrm{~m}\right.$; area $\left.1.24 \mathrm{~m}^{2}\right)$ to which fibreglass window screening (c. $1.5 \mathrm{~mm}$ mesh) was stapled. Enclosures were open at the top and bottom so that tadpoles could forage on the pond bottom and eventually leave the enclosure in the course of metamorphosis. The latter precaution was important because tadpoles often cannibalize metamorphs that fail to leave the water, which would artificially increase estimates of carnivory. To prevent tadpoles from escaping, enclosures were staked to the bottom of the pond and sealed with sediment and bricks placed along a $30 \mathrm{~cm}$-wide fibreglass screening skirt added to the external lower edge of each enclosure. To preserve the structure of vegetation and substratum, enclosures were set on undisturbed substrata and no attempts were made to remove organisms that might have been trapped within the enclosures during setup.

Each enclosure was stocked with a total of 60 tadpoles, 30 of each of two species (either wood and leopard frogs, or bullfrogs and green frogs, due to the constraints of breeding phenology; see below). Densities were chosen based on previous field 
experiments (Werner, 1994; Werner \& Glennemeier, 1999) to be low enough to yield high growth, but high enough to yield an adequate sample of similar-sized individuals. We stocked each enclosure with two species to control for any confounding effects of habitat selection or resource patchiness on diet, to reduce the number of experimental treatments, and to maximize the number of replicate enclosures in a pond.

(b) Spring breeding species. Enclosures were set out on 13-15 June 2001 in two closed- (SWW, WWB) and two open- (FH, IND) canopy ponds. SWW and WWB naturally contained populations of wood frogs, $\mathrm{FH}$ contained populations of both wood and leopard frogs, and IND contained a population of leopard frogs. On 19 June each enclosure was stocked with 30 wood frog larvae [314.8 $\pm 5.2 \mathrm{mg}$ (mean mass $\pm 1 \mathrm{SE}$ )] and 30 leopard frog larvae $(329.5 \pm 15.2 \mathrm{mg})$. Because tadpole cultures differed in periphyton cover and zooplankton densities, which were likely to affect the initial isotopic signatures of tadpoles, the four replicates in each pond were separated in two blocks of tadpole source cultures (i.e. those with high periphyton cover and low zooplankton densities, and those with low periphyton cover and high zooplankton densities, based on a visual assessment). Each of the two blocks was randomly assigned to the four enclosures in each pond. The experiment was ended after 15-17 days, when wood frogs had reached an advanced developmental stage.

(c) Summer breeding species. Enclosures were set out in CR and SWS on 24 August 2001. Both wetlands contained populations of bullfrogs and green frogs. On 28 August 2001, each enclosure was stocked with 30 bullfrog larvae $(294.9 \pm 13.9 \mathrm{mg})$ and 30 green frog larvae $(294.5 \pm 10.0 \mathrm{mg})$. For consistency with the previous experiment, enclosures were also ended after 15-17 days.

At the end of experiments, tadpoles were dip-netted out of the enclosures and immediately killed in 20\% cold ethanol to halt ingestion of additional food and digestion of gut contents. We expected no influence of this procedure on isotopic integrity due to the high dilution of ethanol and the short period of immersion $(<2 \mathrm{~h})$. In the laboratory tadpoles were counted, weighed and assigned to a developmental stage (Gosner, 1960). Most individuals were frozen for later analysis, although a few tadpoles were preserved in $5 \%$ formalin for identification of gut contents.

(d) Field sampling. In order to infer the food sources of free-ranging anuran larvae, during the course of the transplant experiments we sampled the natural populations of anuran larvae in each wetland, and their putative main food sources (phytoplankton, periphyton, detritus, macrophytes), as well as invertebrates found in tadpole gut contents (see the Supporting Information) and organisms of known TL to serve as references in the interpretation of tadpole isotopic signatures.

Phytoplankton from wetlands was filtered from $1 \mathrm{~L}$ of subsurface water using pre-combusted Whatman GF/F filters (Whatman plc, Kent, U.K.) after passing the sample through a $150 \mu \mathrm{m}$ mesh to remove larger zooplankton. These filters were then examined with a stereomicroscope for removal of any large zooplankton that might eventually have passed through the mesh. Periphyton was either scraped from natural surfaces such as logs or macrophytes, or collected from filamentous mats. A variety of aquatic macrophytes was sampled, especially duckweed (Lemna), but also Riccia, Ceratophyllum and Miriophyllum, depending on presence and abundance. In each pond, detritus or sediment (depending on the predominant substratum type) was collected from two to 10 locations and mixed in a bucket. In the laboratory, the bucket was filled with water, vigorously stirred and sieved into four particle size classes: whole leaves (when present), >2 mm, 1-2 mm and $150 \mu \mathrm{m}-1 \mathrm{~mm}$. We employ the term 'detritus' to represent decomposing organic matter of recognizably plant origin, and 'sediment' to represent bed material composed of mixed fine organic matter and inorganic particles that are largely undistinguishable from each other by eye. Macroinvertebrates were removed from periphyton, macrophyte, detritus and sediment samples, or collected with dipnets. Zooplankton was collected with a fine-mesh dipnet and sorted into higher taxonomic categories (Ostracoda, Copepoda, Cladocera). We used planorbid snails as a reference for primary consumers in each pond [Promenetus exacuous (Say, 1821) in SWW and WWB, Planorbella campanulata (Say, 1821) in CR and IND, Planorbella trivolvis (Say, 1817) in FH and SWS]. Snails are suitable reference organisms because their generation times are similar to those of tadpoles and they are benthic primary consumers 
with specialized morphology for grazing on periphyton and detritus (Dillon, 2000; Post, 2002). Invertebrates were held overnight in well water to clear their gut contents before analysis. Vertebrates and macroinvertebrates were frozen; all other organisms and substrata were oven dried at $40{ }^{\circ} \mathrm{C}$. Voucher samples were preserved in $70 \%$ ethanol (invertebrates) or $5 \%$ formalin (vertebrates, substrata).

\section{Laboratory analyses}

Samples of organisms and substrata were analysed for $\delta^{15} \mathrm{~N}$ and $\delta^{13} \mathrm{C}$ using a Finnigan Delta Plus isotope ratio mass spectrometer with a Conflo II interface (Thermo Finnigan, San Jose, CA, U.S.A.). The isotopic composition of a sample was calculated as: $\delta{ }^{13} \mathrm{C}$ or ${ }^{15} \mathrm{~N}(\%)=\left[\left(R_{\text {sample }}-R_{\text {standard }}\right) / R_{\text {standard }}\right] \times 10^{3}$ where $R$ is $\left({ }^{13} \mathrm{C} /{ }^{12} \mathrm{C}\right)$ or $\left({ }^{15} \mathrm{~N} /{ }^{14} \mathrm{~N}\right)$ and standards are atmospheric nitrogen or PD Belemnite carbon (precision $\pm 0.2 \%$ ). We also estimated the nutritional quality of food ingested by tadpoles by analyzing the $\% \mathrm{C}, \% \mathrm{~N}$ and $\mathrm{C}: \mathrm{N}$ mass ratios of the foregut contents of each individual tadpole undergoing isotopic analysis using a Thermo Instrument Flash elemental analyser 1112 series (CE Elantech, Inc. Lakewood, NJ, U.S.A.); precision $\pm 0.05 \%$.

For enclosed tadpoles, we analysed three individuals per species from each of three enclosures per pond. We controlled for potential mass effects on diet by selecting tadpoles weighing c. $1200 \mathrm{mg}$ except for leopard frogs in open-canopy ponds, which weighed c. $3800 \mathrm{mg}$ due to faster growth (see Schiesari, 2004, 2006 for details). As a reference, we also analysed tadpoles of each species from each culture at the start of the experiments. Among free-ranging tadpoles, we analysed up to eight individuals per species per pond. When two species co-occurred in a pond, we paired individuals of both species by body mass across a range of masses.

We analysed heart tissue in vertebrates, thorax muscle in dragonfly nymphs and the soft tissue in snails. Other invertebrates were analysed whole. Macrophytes, detritus, and sediment were homogenized with mortar and pestle prior to analysis.

\section{Data analysis}

(a) Estimation of tadpole trophic level. In each food web we estimated tadpole TL using the formula
$\mathrm{TL}=1+\left[\left(\right.\right.$ tadpole $\delta^{15} \mathrm{~N}-$ snail $\left.\delta^{15} \mathrm{~N}\right) /$ fractionation of ${ }^{15} \mathrm{~N}$ in tadpole] (Post, 2002). Using this formula, if $\delta^{15} \mathrm{~N}_{\text {tadpoles }}=\delta^{15} \mathrm{~N}_{\text {snails, }}$, then $\Delta^{15} \mathrm{~N}_{\text {tadpole-snail }}=0$ and tadpole $\mathrm{TL}=1$ (a strict herbivore). Similarly, if $\delta^{15} \mathrm{~N}_{\text {tadpoles }}=\delta^{15} \mathrm{~N}_{\text {snails }}+{ }^{15} \mathrm{~N}$ fractionation, $\mathrm{TL}=2$ (a primary predator). We statistically tested whether each species' $\Delta^{15} \mathrm{~N}$ deviates from zero (indicating strict herbivory) and from our experimentally determined consumer fractionation of 1.98 (indicating strict carnivory, see Results) using one-sample $t$-tests including all individual larvae of each species in a given pond type, after verifying homogeneity of variances in isotopic composition between ponds.

(b) Feeding niche differentiation. To test for feeding niche differentiation, we conducted ANOVAs for the effects of species identity, pond and a species identityby-pond interaction term on $\delta^{13} \mathrm{C}, \Delta{ }^{15} \mathrm{~N}$ and gut content $\mathrm{C}: \mathrm{N}$ in each species pair (wood and leopard frogs; bullfrogs and green frogs) in the enclosure experiments. We conducted a similar ANOVA comparing all four species in enclosures (with the caveat that in this case $\delta^{13} \mathrm{C}$ and $\mathrm{C}: \mathrm{N}$ differences could be caused by pond or seasonal differences in the availability and isotopic signature of different food types). Because free-ranging tadpoles spanned a range of masses, in ponds where species co-occurred we conducted analyses of covariance (ANCOVA) for the effects of species and pond as main effects, and a species-by-pond interaction, using tadpole mass as a covariate on tadpole $\delta^{13} \mathrm{C}, \Delta^{15} \mathrm{~N}$ and gut content $\mathrm{C}: \mathrm{N}$. In all cases we employed Tukey's multiple comparisons tests followed by Bonferroni adjustments.

\section{Results}

Calibration of isotopic fractionation

The isotopic fractionation of larval wood frog heart tissue relative to rabbit food was $1.98 \pm 0.17 \%$ for $\delta^{15} \mathrm{~N}$, and $1.69 \pm 0.12 \%$ for $\delta^{13} \mathrm{C}(n=4)$. We employ this fractionation factor for all larval anuran species in the study.

\section{Evidence for carnivory}

Since all species can be found in open-canopy ponds but only wood frogs naturally occur in closed-canopy ponds, our initial comparisons across species are 

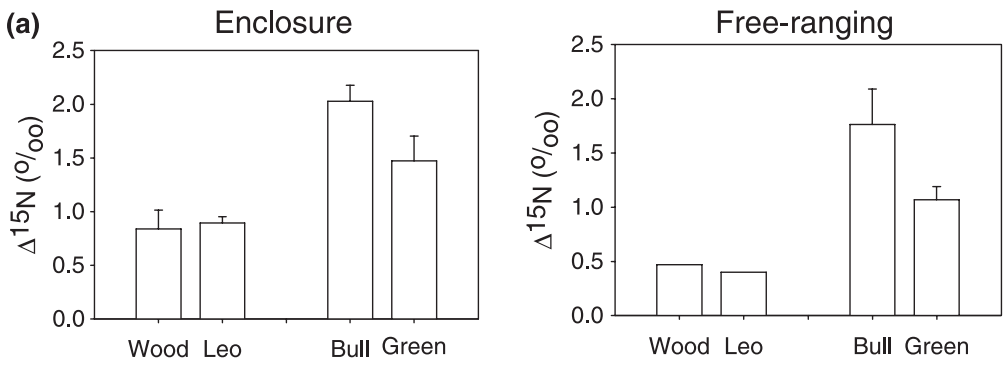

Fig. 1 (a) $\Delta^{15} \mathrm{~N}$ (b) $\delta^{13} \mathrm{C}$ and (c) foregut content $\mathrm{C}: \mathrm{N}$ ratios (by mass) of enclosed (left) and free-ranging (right) anuran larvae of four ranid species in open-canopy ponds. In a, a value of zero in the $y$-axis would imply that tadpoles are strict herbivores, whereas a value of 1.98 would imply that tadpoles are primary predators (see text for explanation). Each bar represents the grand mean \pm 1 SE of two ponds, except for free-ranging wood frog and leopard frog larvae, which were sampled in a single pond each.
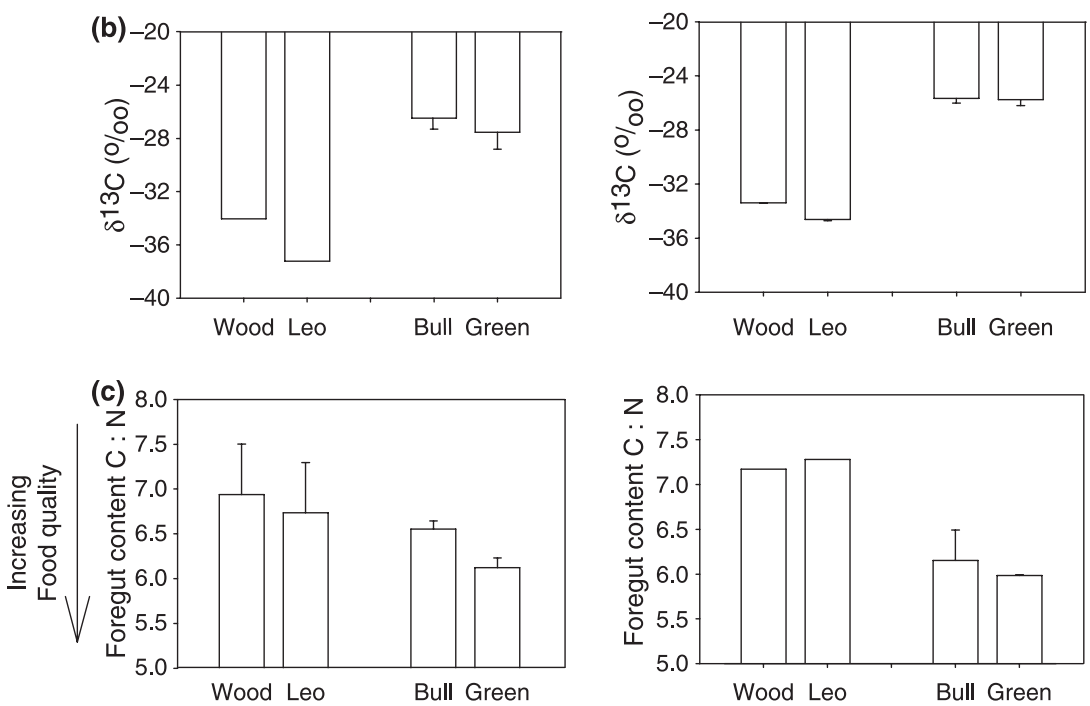

based exclusively on individuals from open-canopy ponds. All species displayed some degree of carnivory (Fig. 1a). Among enclosed larvae, one-sample $t$-tests indicated that $\Delta^{15} \mathrm{~N}$ was significantly greater than zero for all species (marginally so for wood frogs), but was significantly smaller than $1.98 \%$ for all species except bullfrogs. Similar results were observed among free-ranging larvae, except that wood frog and leopard frog $\Delta^{15} \mathrm{~N}$ did not differ from zero.

\section{Evidence for resource-based niche differentiation,} ontogenetic niche shifts and opportunistic diet.

We address these questions separately for spring and summer breeders in order to minimize the confounding effects of seasonal differences in resources. Appendix S1 details the isotopic signatures of enclosed and free-ranging tadpoles, as well as the $\mathrm{C}: \mathrm{N}$ ratios of their gut contents. A summary of results is presented below.

(a) Spring-breeding species. The null hypothesis of a lack of feeding niche differentiation between enclosed wood and leopard frog larvae in open-canopy ponds was refuted by the significant differences among species in $\delta^{13} \mathrm{C}$, but not in $\Delta^{15} \mathrm{~N}$ or gut content $\mathrm{C}: \mathrm{N}$ (Fig. 1; Table 1). In turn, the hypothesis of opportunistic diet was supported by significant pond effects on gut content $\mathrm{C}: \mathrm{N}$ only, as the nutritional quality of food ingested was higher in IND than in FH (lower $\mathrm{C}: \mathrm{N}$ indicates higher quality food). There were no significant species-by-pond interaction terms. A significant block effect in isotopic composition was observed because tadpoles originating from zooplankton-rich cultures were slightly enriched in ${ }^{15} \mathrm{~N}$ and ${ }^{13} \mathrm{C}$ compared to tadpoles from zooplankton-poor cultures.

Free-ranging leopard frog larvae were depleted in ${ }^{13} \mathrm{C}$ relative to wood frog larvae, paralleling the results observed in the enclosures and suggesting differentiation in sources of carbon. However, this comparison has little power as the two species came from different ponds. No differences in $\Delta^{15} \mathrm{~N}$ were found between free-ranging wood frog and leopard frog larvae (Fig. 1; independent samples $t$-test d.f. $=5, t=0.142$, $P=0.892$ ). 
Table 1 Results of ANOVAs for the effects of species identity, pond and a species identity-by-pond interaction term on $\Delta^{15} \mathrm{~N}$ and $\delta^{13} \mathrm{C}$ isotopic composition, and foregut content $\mathrm{C}: \mathrm{N}$ ratio of enclosed larvae in open-canopy ponds

\begin{tabular}{|c|c|c|c|c|c|}
\hline & $\Delta^{15} \mathrm{~N}$ & & $\delta^{13} \mathrm{C}$ & & $C: N$ \\
\hline Factor & d.f. $F$ & $P$-value & $F$ & $P$-value & $P$-value \\
\hline
\end{tabular}

(a) Wood frogs and leopard frogs

\begin{tabular}{|c|c|c|c|c|c|c|c|}
\hline SP & 1 & 0.01 & 0.942 & 7.77 & 0.009 & 1.07 & 0.310 \\
\hline Pond & 1 & 0.28 & 0.603 & 0.38 & 0.540 & 32.40 & 0.000 \\
\hline Block & 1 & 13.49 & 0.001 & 7.45 & 0.010 & 2.11 & 0.156 \\
\hline $\mathrm{SP} \times$ pond & 1 & 0.15 & 0.704 & 0.15 & 0.701 & 0.00 & 0.985 \\
\hline \multicolumn{8}{|c|}{ b) Bullfrogs and green frogs } \\
\hline SP & 1 & 17.63 & 0.000 & 0.05 & 0.824 & 9.00 & 0.005 \\
\hline Pond & 1 & 8.67 & 0.006 & 3.40 & 0.074 & 1.97 & 0.170 \\
\hline $\begin{array}{l}\text { SP } \times \text { pond } \\
\text { c) All specie }\end{array}$ & 1 & 0.41 & 0.527 & 0.03 & 0.853 & 0.01 & 0.904 \\
\hline \multirow[t]{2}{*}{$\mathrm{SP}$} & 3 & 8.14 & 0.000 & 273.76 & 0.000 & 5.05 & 00 \\
\hline & & $\underline{W} \mathrm{~L}$ & G B & $\underline{W} L$ & $\underline{B G}$ & $\underline{W} \mathrm{~L}$ & \\
\hline
\end{tabular}

In (C) pairwise interspecific comparisons based on Bonferroniadjusted Tukey's multiple comparisons test are presented. Species linked by continuous underlining do not differ statistically. Differences between species linked by hatched underline were marginally insignificant $(P<0.07)$.

SP, species; W, wood frogs; L, leopard frogs; B, bullfrogs; G, green frogs. Non-significant interaction terms were dropped from the analyses.

(b) Summer-breeding species. Significant differences among species were found in the degree of carnivory $\left(\Delta^{15} \mathrm{~N}\right.$ was $37 \%$ higher in bullfrog larvae) and in the nutritional quality of food ingested $(\mathrm{C}: \mathrm{N}$ was $7 \%$ higher in bullfrog larvae) but not in $\delta^{13} \mathrm{C}$. These results refute the null hypothesis of lack of feeding niche differentiation between summer-breeding species in enclosures (Fig. 1; Table 1). An opportunistic diet was suggested by significant pond effects for $\Delta^{15} \mathrm{~N}$ and marginally significant pond effects for $\delta^{13} \mathrm{C}$ (tadpoles in SWS were enriched in ${ }^{15} \mathrm{~N}$ but depleted in ${ }^{13} \mathrm{C}$ relative to tadpoles in $\mathrm{CR}$ ). No species-by-pond interaction terms were observed for any response variable.

Isotopic evidence refuting a lack of niche differentiation was even stronger in free-ranging larvae (Figs 1 \& 2). Bullfrog larvae had higher $\Delta^{15} \mathrm{~N}(74 \%$ higher; ANCOVA $\left.F_{1,24}=6.14, P=0.022\right)$ and higher $\delta^{13} \mathrm{C}$ $\left(F_{1,24}=10.69, P=0.004\right)$ than green frog larvae. Nevertheless, species did not differ in gut content $\mathrm{C}: \mathrm{N}$ $\left(F_{1,24}=1.38, P=0.254\right)$. There were main effects of ponds on gut content $\mathrm{C}: \mathrm{N}$ only $\left(F_{1,24}=7.29\right.$, $\left.P=0.014 ; \Delta^{15} \mathrm{~N} P=0.400,{ }^{13} \mathrm{C} P=0.473\right)$, as the food consumed in $\mathrm{CR}$ was of significantly higher quality

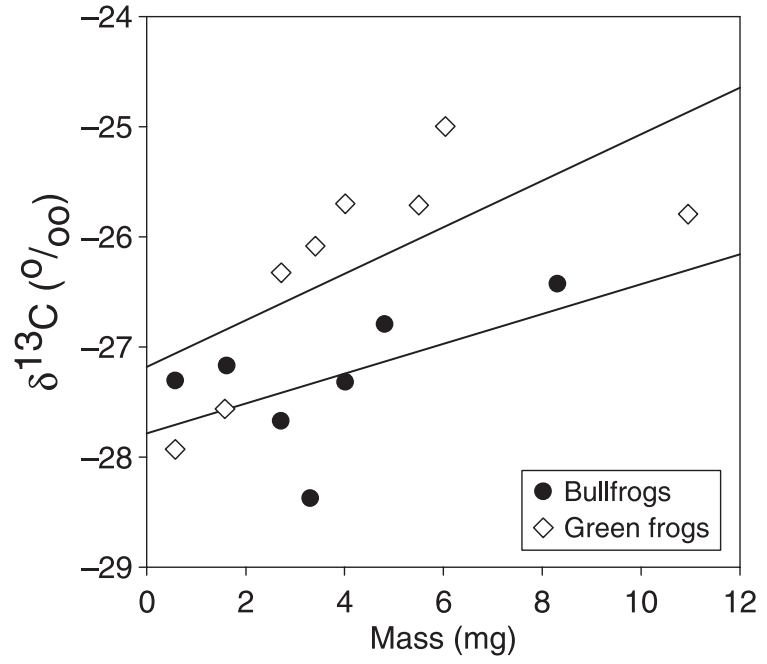

Fig. 2 Relationship between $\delta^{13} \mathrm{C}$ and body mass in free-ranging bullfrog and green frog larvae in Crane Pond

$\left(\delta^{13} C_{\text {green }}=-27.181+0.000211 \times\right.$ mass, $P=0.06, R^{2}=0.47$;

$\delta^{13} C_{\text {bull }}=-27.79+0.000136 \times$ mass, $\left.P=0.20, R^{2}=0.30\right)$.

than that in SWS. Significant species identity-by-pond interaction terms were detected for $\delta^{13} \mathrm{C}\left(F_{1,24}=36.96\right.$, $P<0.001)$ and $\mathrm{C}: \mathrm{N}\left(F_{1,24}=5.29, P=0.032\right)$ but not for $\Delta{ }^{15} \mathrm{~N}(P=0.141)$. These interaction terms arose because species $\delta^{13} \mathrm{C}$ differences occurred in opposite directions in different ponds, and because food quality ingested by both species was similar in CR but not in SWS. Therefore, species exhibited a considerably opportunistic diet (Fig. 3). Ontogenetic shifts in diet were suggested by the nearly significant mass effect on tadpole $\delta^{13} \mathrm{C}\left(F_{1,24}=4.14, P=0.055\right.$; Fig. 2$)$. No mass effects were observed for $\Delta^{15} \mathrm{~N}(P=0.664)$ or gut content $\mathrm{C}: \mathrm{N}\left(F_{1,24}=0.59, P=0.453\right)$.

(c) All species. When comparing all four species in open-canopy pond enclosures, species identity had significant effects on tadpole $\delta^{13} \mathrm{C}, \Delta{ }^{15} \mathrm{~N}$ and gut content $\mathrm{C}: \mathrm{N}$ ratios (Table 1). Bonferroni-adjusted Tukey's multiple comparisons tests indicated significant interspecific differences in four out of six pairwise combinations for $\delta^{13} \mathrm{C}$, in two out of six combinations for $\Delta^{15} \mathrm{~N}$, and in one out of six combinations for gut content $C: N$ ratios.

\section{Pond food webs and food sources for anuran larvae}

We inferred food web structure and food sources for the anuran larvae from the isotopic and gut content analyses of free-ranging individuals from all six ponds 

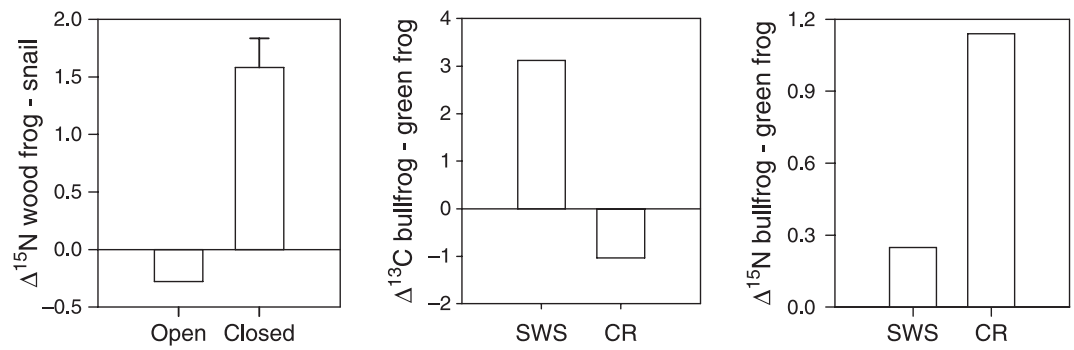

Fig. 3 Evidence for an opportunistic diet in free-ranging anuran larvae. (a) Comparison of the $\Delta^{15} \mathrm{~N}$ of wood frog larvae relative to snails in closed-canopy ponds and in open-canopy ponds. Comparison of the (b) $\Delta^{13} \mathrm{C}$ and (c) $\Delta{ }^{15} \mathrm{~N}$ of bullfrog larvae relative to green frog larvae in Southwest Swamp and in Crane pond.

(including a comparison of open- and closed-canopy ponds which have very different resource bases). These results, detailed in Appendix S2, are summarized below.

(a) Wood frog larvae in closed-canopy ponds. The wood frog was the only larval anuran species consistently found in closed-canopy ponds. Detritus accounted for the majority of the volume of gut contents of wood frogs in closed-canopy ponds. Relative to detritus, wood frog larvae were enriched in ${ }^{15} \mathrm{~N}$ by $3.5-3.9 \%$ but depleted in ${ }^{13} \mathrm{C}$ by $2-3.5 \%$ (ranges of mean signatures per pond; see Fig. 4a for WWB). Therefore, because fractionation factors should be positive for both ${ }^{15} \mathrm{~N}$ and ${ }^{13} \mathrm{C},{ }^{15} \mathrm{~N}$ but not ${ }^{13} \mathrm{C}$ isotopic signatures support an important role for detritus in larval wood frog nutrition. Further, invertebrates (probably within the detritus) clearly appear to be an important nutritional source. This inference is supported by the observation that ${ }^{15} \mathrm{~N}$ signatures of wood frog larvae were higher than those of most invertebrates sampled, higher than those of reference herbivores $\left(\Delta^{15} \mathrm{~N}_{\text {wood }}\right.$ frogs-snails $=1.14$ $1.46 \%$ ), and comparable to those of predatory Ambystoma salamander larvae (one of these a $37 \mathrm{~g}$ A. tigrinum Green, 1825) $\left(\Delta^{15} \mathrm{~N}_{\text {wood }}\right.$ frogs-salamanders $=-0.06$ to $0.23 \%$ ). Furthermore, invertebrates were commonly found in wood frog guts (ostracods in more than half of the guts dissected; other animal observed were protozoans, rotifers, copepods and molluscs) although never dominant by volume. Duckweed (Lemna spp.) consumption cannot account for the high values of wood frog $\delta^{15} \mathrm{~N}$ because duckweed species were found in WWB only, and they were not a common item in tadpole guts.

(b) Wood frog and leopard frog larvae in open-canopy ponds. Gut contents of wood frog larvae were dom- inated in volume by detritus and sediments, with frequent occurrences of filamentous algae and ostracods. Nitrogen isotopic signatures suggest that in open-canopy ponds the wood frog larva was a primary consumer: it was on average enriched by $1.68 \%$ relative to detritus and sediment and by $2.2 \%$ relative to periphyton, but similar to the snail Planorbella $\left(\Delta^{15} \mathrm{~N}_{\text {wood frog-snails }}=-0.28 \%\right.$ ) and depleted relative to predatory dragonfly naiads $(-2.90 \%)$ and salamander larvae $(-1.65 \%)$ (Fig. $4 \mathrm{~b})$. The sources of carbon remain uncertain, as the wood frog larva was depleted in ${ }^{13} \mathrm{C}$ by $3.2 \%$ relative to detritus and sediments and similar to the average $\delta^{13} \mathrm{C}$ signatures of two periphyton taxa. These isotopic results were based on a single tadpole; however, similar patterns were observed in the same pond the previous year where more individuals were analysed. For example, in 2000 larval wood frog $\delta^{13} \mathrm{C}$ coincided with that of a periphyton aggregate; but tadpoles were enriched in ${ }^{15} \mathrm{~N}$ by $2.38 \%$ relative to the periphyton.

Gut contents of leopard frog larvae were dominated by detritus and filamentous algae, but also frequently contained insect and plant fragments. Leopard frog larvae exhibited considerable individual variation in $\delta^{13} \mathrm{C}$ and were depleted relative to any other organism or substratum sampled; nevertheless, a primary consumer role is suggested by the observation that tadpole $\delta^{15} \mathrm{~N}$ was only slightly higher than that of the snail Planorbella, and higher than macrophytes and sediments.

(c) Bullfrog and green frog larvae in open-canopy ponds. Gut contents of bullfrog larvae were dominated by sediments, with important contributions of algae and invertebrates (particularly protozoans, microcrustaceans and insects). Green frog larvae gut contents were dominated by sediments and filamen- 

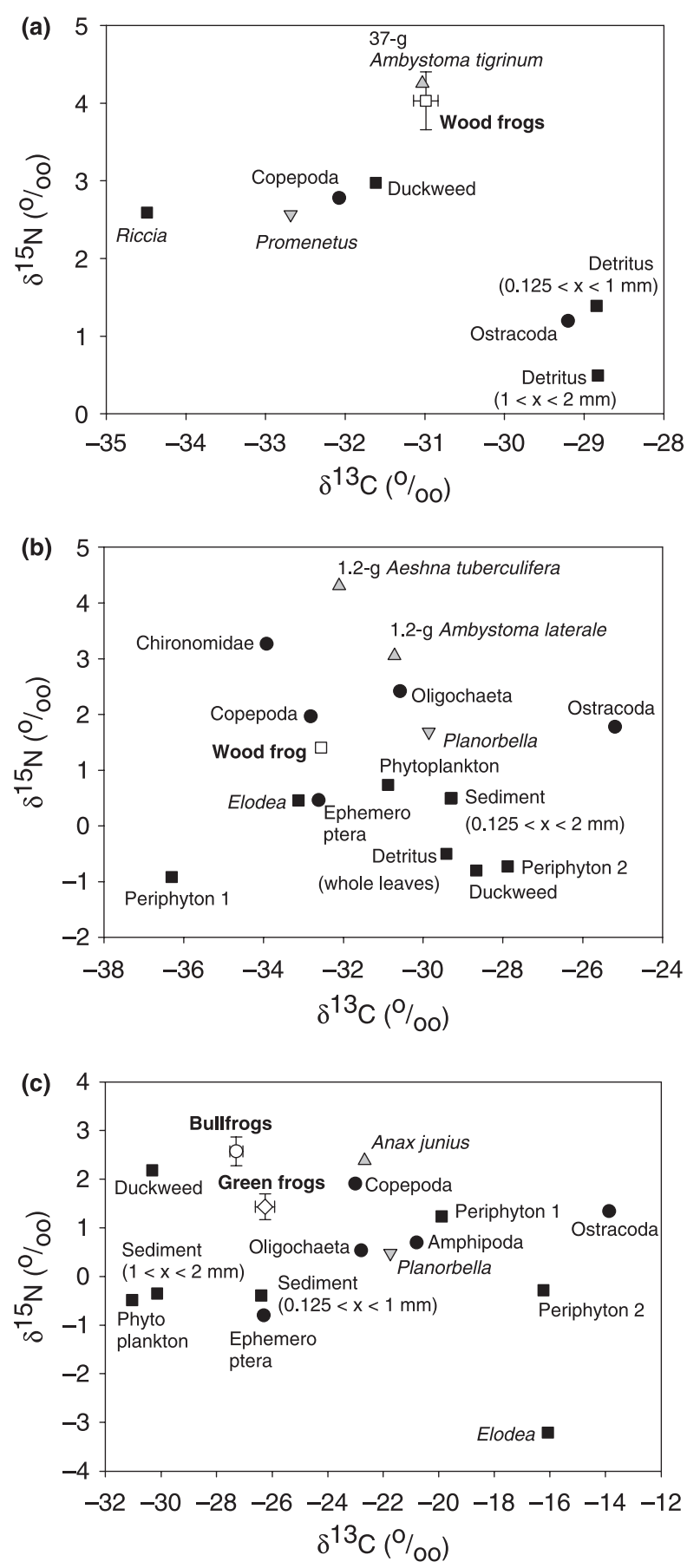

tous algae; plant fragments and invertebrates were also common. Relative to sediments, bullfrog larvae were enriched in both ponds in ${ }^{13} \mathrm{C}(0.6-0.9 \%)$ and ${ }^{15} \mathrm{~N}$ (2.5-3.1\%o) (Fig. 4c). Green frog larvae were enriched in ${ }^{15} \mathrm{~N}(1.9-2.3 \%)$; they were also enriched in ${ }^{13} \mathrm{C}$ in $\mathrm{CR}(+2.0 \%)$ but not in SWS $(-2.5 \%)$. Tadpoles of both species were enriched in ${ }^{15} \mathrm{~N}$ relative to snails (bullfrogs $1.4-2.1 \%$; green frogs $1.0-1.2 \%$ )
Fig. 4 Carbon ( $x$-axis) and nitrogen (y-axis) isotopic signatures of representative organisms and substrates in pond food webs. (a) West Woods Big Pond, a closed-canopy temporary pond containing wood frogs (five individuals averaging $0.91 \mathrm{~g}$, range $0.72-1.10 \mathrm{~g}$ ). (b) Fishhook Marsh, an open-canopy semi-permanent pond containing wood frogs (one individual weighing $2.07 \mathrm{~g}$ ) and (c) Crane Pond, an open-canopy permanent pond containing bullfrogs (seven individuals averaging $3.62 \mathrm{~g}$, range $0.57-8.31 \mathrm{~g}$ ) and green frogs (eight individuals averaging $4.35 \mathrm{~g}$, range $0.57-10.95 \mathrm{~g}$ ). Open symbols represent tadpoles (squares: wood frogs; circles: bullfrogs; diamonds: green frogs) (average $\pm 1 \mathrm{SE})$. Gray triangles represent reference carnivores (Ambystoma are salamander larvae, Aeshna and Anax are dragonfly nymphs), inverted grey triangles represent reference herbivores (Promenetus and Planorbella are snails). Black circles represent other animals, and black squares represent basal resources (primary producers, detritus and sediment).

and comparable to or depleted relative to Anax dragonfly naiads (bullfrogs -1.1 to $0.2 \%$; green frogs -1.0 to $-1.4 \%$ ). Therefore, both isotopic and gut content analyses strongly suggest that bullfrog larvae, and to a lesser extent green frog larvae, are predators in pond food webs with a diet based on invertebrates feeding on sediments. Tadpole nutrition appears to be supplemented by sediments, detritus and algae.

\section{Discussion}

This study provides strong evidence for carnivory, feeding niche differentiation and opportunism in diet among morphologically generalized anuran larvae. It also provides some evidence for the occurrence of ontogenetic niche shifts in their diet. Our findings additionally suggest a complexity in trophic interactions in pond food webs that is little appreciated, with important implications for the way in which we design and interpret ecological experiments involving anuran larvae.

Our estimates of TL demonstrate that all four ranid species incorporate substantial fractions of animal matter in their diets and therefore exhibit varying degrees of omnivory. Bullfrog larvae, and possibly wood frog larvae in closed-canopy ponds, in particular appear to be effectively functioning as primary predators in pond food webs. Other species exhibit varying degrees of omnivory, with green frogs consuming more animal matter than leopard frogs and open-canopy pond wood frogs.

We consider these TL inferences robust. Inferences of TL using stable isotopes are sensitive to the $\delta^{15} \mathrm{~N}$ 
fractionation factor employed (Post, 2002), and the $\delta^{15} \mathrm{~N}$ fractionation factor measured in our study $(1.98 \%$ o $)$ is lower than the average $3.4 \%$ value reported by Post (2002). However, it should yield more accurate estimates of TL because it was measured in controlled laboratory experiments with one of the same species of larval anuran analysed in this study, and not based on an average of various species of consumers in both controlled laboratory studies and uncontrolled field studies. Perhaps more important, similar estimates of TL would be obtained if predators instead of primary consumers were used as reference organisms. For example, the $\delta^{15} \mathrm{~N}$ of free-ranging wood frog larvae equalled (and sometimes exceeded) that of predatory salamander larvae in closed-canopy ponds; one of these was a tiger salamander 40 times heavier than the wood frogs sampled (Fig. 4a). Similarly, the $\delta^{15} \mathrm{~N}$ of several individual bullfrog larvae equalled that of dragonfly nymphs (Fig. 4c). Note that these results underscore the extent of carnivory by anuran larvae, because salamander larvae and dragonfly nymphs consume both primary consumers and other carnivores (e.g. Corbet, 1999; Yurewicz, 2002). It is also very unlikely that the TL estimates in tadpoles could be artificially increased through the transfer of ${ }^{15} \mathrm{~N}$-enriched material from their predatory mothers during ovulation. This is because any isotopic differences would have been diluted as tadpoles mass increased over 100 times since hatching, and because we selected a fast turnover tissue for analysis precisely to reflect short term dietary incorporation of matter.

Consumption of animal matter by tadpoles is perhaps not surprising given observations of oophagy, necrophagy and occasional carnivory dating since Boulenger's classic study of European tadpoles (Boulenger, 1898; Savage, 1952; more recent reviews include Hoff et al., 1999; Alford, 1999; Petranka \& Kennedy, 1999; Altig et al., 2007). However, the extent to which incorporation of animal matter is important to tadpole tissue biosynthesis, and the high TL estimates revealed in this study, are remarkable. The isotopic information does not permit us to differentiate among strict predation, oophagy, cannibalism, necrophagy and incidental consumption of animal matter amid sediment and periphyton. All may occur, as all species in our study contained invertebrates in their guts (see Appendix S2), and are known to consume anuran eggs, embryos and dead or mori- bund tadpoles (reviewed in Petranka \& Kennedy, 1999). However, oophagy, cannibalism and necrophagy are unlikely to be the only or even major source of animal matter for the anuran larvae in our study for three reasons. First, no eggs or tadpole tissues were found in the guts of free-ranging larvae. Secondly, no egg-laying by amphibians occurred in the enclosures over the course of the experiment, and therefore oophagy could not be important among enclosed tadpoles. It is also unlikely that oophagy contributed to the high TL estimates for free-ranging wood frogs in closed-canopy ponds because no other amphibian species oviposited after wood frogs in this pond type at our study site. Thirdly, if necrophagy or cannibalism were the predominant sources of animal matter in larval nutrition, one would expect that tadpole $\Delta^{15} \mathrm{~N}$ would be negatively correlated with survivorship across enclosures within a pond. This relationship was significant for only one out of eight species-bypond combinations (L. Schiesari, unpubl. data). In contrast, guts of all species (and especially bullfrogs) contained many protozoans, microcrustaceans and insects, some of which were intact and likely to have been consumed live. Microcrustaceans were found in more than half of the guts of all species analysed, and insects occurred in more than half of leopard frog and bullfrog guts (see Appendix S2). These observations suggest that consumption of invertebrates is a sufficient explanation for the high estimates of carnivory in these anuran larvae.

In addition to consumption of animal matter, different species of ranid larvae appear to derive their nutrition from sediments and algae to varying degrees. The very strong convergence of bullfrog and green frog $\delta^{13} \mathrm{C}$ to that of sediments (also the prevailing item in their guts) suggests that bullfrogs and green frogs derive their carbon primarily from sediments, and especially (given high TL estimates) from invertebrates feeding on the sediments. Based on isotopic and gut content analyses, algae may be secondarily important to nutrition, especially for green frogs. This is in opposition to Seale \& Beckvar (1980) and Seale (1980), who found that bullfrog larvae (among other species) had excellent filterfeeding abilities and were largely consuming phytoplankton and other suspended particulate organic matter in a productive pond ecosystem. Such differences are a further argument for the opportunism in tadpole diets documented in this and other studies 
(see Alford, 1999 for a review). Wood frog isotopic signatures and gut content analyses suggest a heavy reliance on periphytic algae in productive opencanopy ponds, whereas wood frog guts are virtually filled with particulate and amorphous detritus in closed-canopy ponds, and the species grows well on this food type (Schiesari, 2004). Nonetheless, wood frogs were depleted in ${ }^{13} \mathrm{C}$ relative to detritus, and not enriched as the calibration experiment would suggest. These results may indicate that wood frogs are deriving a considerable fraction of their nutrition from other, more depleted food sources, which are present but undetected amid leaf-litter (e.g. because they are diluted by the isotopic signature of the larger biomass of non-digestible matter). For example, bacteria growing on detritus account for only $1 \%$ of detritus biomass (Moriarty \& Pullin, 1987), but together with fungal hyphae constitute the most likely nutritional sources for anurans in detritus. In support to this hypothesis, methanotrophic bacteria are common in wetland sediments and are strongly depleted in ${ }^{13} \mathrm{C}$ (Grey et al., 2004). Thus, consumption of microscopic fractions of detritus, and invertebrates, probably constitutes the main nutritional sources for wood frogs in closed-canopy ponds.

This study provides abundant evidence that tadpoles display not only food selectivity and feeding niche differentiation with respect to TL and nutritional quality of food ingested, but also the sources of assimilated carbon in some cases. Feeding niche differentiation appears to be in part associated with suites of behavioural, morphological and physiological traits in these species. For example, the summerbreeding bullfrogs and green frogs consumed more invertebrates and also had shorter guts, more heavily keratinized mouthparts, higher minimum nutrient requirements, and lower activity rates than the spring-breeding wood and leopard frogs (Schiesari, 2004). These traits suggest that carnivory is a means of satisfying higher metabolic demands while maintaining low activity, which is important for lowering predation risk in permanent ponds where predators are abundant (Skelly, 1996). Behavioural differences such as those related to microhabitat choice also might account for differences in sources of carbon; for example, green frogs are more benthic than bullfrogs, which are commonly observed in the water column and among macrophytes in natural ponds (Werner \& McPeek, 1994). This trend also may explain the greater consumption of filamentous algae in the former and phytoplankton in the latter.

The concept of interspecific niche differentiation among anuran larvae is not new, but was dominated by studies documenting partitioning of space (macrohabitat and microhabitat) and time (seasonal) (e.g. Heyer, 1973, 1974, 1976; Werner \& McPeek, 1994). Detailed comparative studies of the morphology of oral and buccopharyngeal structures (e.g. Wassersug, 1980; Viertel, 1982) and the mechanics of suspension feeding (Seale \& Wassersug, 1979; Seale \& Beckvar, 1980; Viertel, 1990) suggest that species have differential abilities to harvest food according to particle size, and, as such, may exhibit resource-based niche differentiation. Nevertheless, even species differing markedly in morphology ingest food particles with similar or even indistinguishable particle size frequency distributions (Heyer, 1973, 1974; Seale, 1980). A few studies identifying items found in the guts of co-occurring tadpole species also point to occasional resource based differentiation (e.g. Rossa-Feres, Jim \& Fonseca, 2004). The isotopic analysis of free-ranging and enclosed larvae in replicated wetlands that we present in this study strongly suggests that resourcebased niche differentiation occurs among coexisting tadpoles species.

Our results have important implications for understanding the structure of pond food webs in that they emphasize that tadpoles - usually considered herbivorous and detritivorous - may exert substantial predation pressure on invertebrates. This pressure could be collectively high even if invertebrates are rarely numerically dominant in gut contents because tadpoles can reach high densities in ponds (for instance, a range of $0.25-116$ wood frogs per $\mathrm{m}^{2}$ in closed-canopy ponds, Werner et al., unpubl; see also Woodward, 1982), and they can process an enormous volume of food due to high gut clearance rates (0.3$2 \mathrm{~h}$ depending on species and food type; Schiesari, 2004). Such a predatory role of tadpoles in pond food webs was demonstrated in laboratory and artificial pond experiments by Petranka \& Kennedy (1999); our isotopic results extend their evidence to food webs in natural ponds and demonstrate that carnivory is not occasional, but a regular habit in several species of amphibian larvae with generalized morphology.

Our study also supports Petranka \& Kennedy's (1999) assertion that extensive carnivory in tadpoles may force us to reinterpret experiments employing 
anuran larvae as model systems and investigating conceptual issues in ecology. For example, several studies have investigated the role of priority effects in community assembly by manipulating tadpoles at different developmental stages (i.e. including hatchlings and large-sized tadpoles; e.g. Wilbur \& Alford, 1985). Diminished population performance of species introduced as hatchlings was attributed to inferior competitive ability and not to cannibalism (a possible alternative explanation for the same pattern given our data). Our data also question the practice of employing ranid anuran larvae as 'grazers' in zooplankton mesocosm experiments to cycle back to the water column the nutrients that end up incorporated in the periphyton (Leibold \& Wilbur, 1992; M.A. Leibold, pers. comm), as they could influence zooplankton abundance and composition not only through indirect facilitation but also through direct predation (which is evidenced here both by gut content and stable isotope analysis of free-ranging tadpoles, and of tadpoles in cultures varying in zooplankton density).

Finally, by demonstrating extensive feeding opportunism and niche differentiation among morphologically generalized anuran larvae, this study also helps us understand why experimental venue may have such a strong influence on the outcome of ecological experiments with anuran larvae. For example, a meta-analysis of over 50 studies and a subsequent empirical test indicated that the effects of interspecific competition were much stronger in mesocosms than in field enclosures, even when tadpole densities and spatial scale were held constant (Skelly \& Kiesecker, 2001; Skelly, 2002). Thus, the prevailing view that competition is a major factor structuring amphibian assemblages was strongly dependent on experimental venue and perhaps of secondary importance in nature. This alleged lack of realism in mesocosms experiments has raised passionate criticism by other experimentalists (e.g. Chalcraft et al., 2005). Our results suggest that perhaps the resources manipulated in laboratory and mesocosm experiments rarely provide the diversity of food found in natural systems that would permit expression of niche differentiation or opportunistic feeding that we observed in the field. Further, feeding niche differentiation as demonstrated here provides a possible explanation for why, as venue becomes more natural and resources become more diverse, evidence for competition diminishes. This diminishing competition may reach the point that growth and developmental rates of several anuran species in natural, productive ponds are largely independent of the density of inter and intraspecific competitors (E. E. Werner, R. Relyea, D. K. Skelly \& K. L. Yurewicz, unpubl. data).

A simple improvement in experimental design relates to food nutritional quality. Artificial diets manipulated in experiments with larval anurans typically consist of rabbit food, fish flakes or mixtures of these ingredients (see e.g. Morin, 1983; Werner, 1991; Arendt, 2003). Rabbit food contains approximately 16\% protein (Purina Mills, St Louis, MO, U.S.A.) and when mixed with fish flakes at a $3: 1$ ratio it is c. $23 \%$ protein (TetraMin; Tetra, Melle, Germany). This protein content is unrealistically low when compared to food ingested in nature. Multiplying foregut content $\% \mathrm{~N}$ by 6.25 (Sterner \& Elser, 2002), we can estimate the mean protein content of food ingested by free-ranging anuran larvae in opencanopy ponds as 31\% (leopard frogs), 33\% (wood frogs), 39\% (bullfrogs) and 44\% (green frogs). Even in the relatively unproductive closed-canopy ponds, the mean protein content of food ingested by wood frogs exceeds $26 \%$. That is, mean protein content of food ingested in nature always exceeds that usually provided in the laboratory or in mesocosms, and sometimes by twofold. Because species ranks in performance, foraging behaviour or predator avoidance behaviour may reverse across resource quality gradients (i.e. species that grow fastest or move most often relative to other species in resource-rich environments may be the ones growing slowest or moving least often in resource-poor environments; Schiesari, 2004), the range of food quality manipulated can alter outcomes of experiments that depend on interspecific comparisons. For example, foragers reduce activity rates with increasing resource quantity or quality because they can acquire sufficient nutrients at reduced predation risk (Werner \& Anholt, 1993; Schiesari, 2004). However, species differ in the scope of this activity response and, as such, one species could be the most or the least active among all others depending on resource conditions, influencing interspecific ranks of any fitness indicator (growth, development, survivorship; Schiesari, 2004). We suggest that these considerations related to artificial foods used in experiments, compared to natural situations where both food quality and diversity may be quite different, should be addressed in future experimental manipulations using anuran larvae. 
The nutrition of anuran larvae is still one of the least-known aspects of amphibian biology, yet is of paramount importance to understanding the ecology and evolution of amphibians (Wassersug, 1975). The larval phase is a period devoted to growth, and many species increase in mass three to four orders of magnitude during this period (Werner, 1986). Furthermore, for many species demographic performance is closely linked to metamorphic success (Berven, 1990). Therefore, there must be very strong selection for the efficient choice, harvesting and processing of food. This study emphasizes that, as in many other taxa, resource differentiation can be substantial in closely related coexisting species and suggests that amphibian larvae may have substantial impacts both as primary consumers and predators in pond food webs. This diversity of feeding relations also suggests that the design and interpretation of experiments with larval anurans will require more care. Given that larvae of phylogenetically related, morphologically generalized anurans exhibit feeding niche and TL differentiation in species-poor communities appears to underscore the importance of complex trophic interactions in some tropical locations, where a remarkable diversity of tadpole ecomorphotypes coexist (Altig \& Johnston, 1989).

\section{Acknowledgments}

We thank Don Zak and Bill Holmes for the isotopic analysis and Jana Gastellum for C:N analysis. Arthur Cooper, Mike Frederick and Chris Davis helped in the fieldwork. We also thank Ronald Nussbaum and the Museum of Zoology of the University of Michigan for permission to work at the ESGR and Faye Stoner, Matthew Heumann and Washtenaw County Parks for permission to work in Independence Marsh. This research was supported by grants from the American Society of Ichthyologists and Herpetologists (Gaige Fund Award), the American Museum of Natural History (Theodore Roosevelt Memorial Fund), The University of Michigan, the National Science Foundation (DEB-0423385 and DEB-9911278), and the Brazilian Government's Conselho Nacional de Desenvolvimento Científico e Tecnológico (200093/97-5). The comments of David Allan, Rick Lehtinen, Shannon McCauley, Mara Zimmerman, Britta Grillitsch, Akane Uesugi and Richard
Wassersug greatly improved the manuscript. The experiments reported here comply with all current laws of the U.S.A.

\section{References}

Abrams P., Menge B.A., Mittelbach G.G., Spiller D.A. \& Yodzis P. (1996) The role of indirect effects in food webs. In: Food Webs: Integration of Pattern and Dynamics (Eds G.A. Polis \& K.O. Winemiller), pp. 371-395. Chapman and Hall, New York.

Alford R.A. (1999) Ecology: resource use, competition, and predation. In: Tadpoles - The Biology of Anuran Larvae (Eds R.W. McDiarmid \& R. Altig), pp. 240-278. University of Chicago Press, Chicago, IL.

Altig R. \& Johnston G.F. (1989) Guilds of anuran larvae: relationships among developmental modes, morphologies, and habitats. Herpetological Monographs, 3, 81109.

Altig R., Whiles M.R. \& Taylor C.L. (2007) What do tadpoles really eat? Assessing the trophic status of an understudied and imperiled group of consumers in freshwater habitats. Freshwater Biology, 52, 386-395.

Arendt J.D. (2003) Reduced burst speed is a cost of rapid growth in anuran tadpoles: problems of autocorrelation and inferences about growth rates. Functional Ecology, 17, 328-334.

Berven K.A. (1990) Factors affecting population fluctuations in larval and adult stages of the wood frog (Rana sylvatica). Ecology, 71, 1599-1608.

Boulenger G.A. (1898) The Tailless Batrachians of Europe. The Ray Society, London.

Chalcraft D.R., Binckley C.A. \& Resetarits W.J. Jr (2005) Experimental venue and estimation of interaction strength: comment. Ecology, 86, 1061-1067.

Corbet P.S. (1999) Dragonflies: Behavior and Ecology of Odonata. Cornell University Press, Ithaca, NY.

Dillon R.T. Jr (2000) The Ecology of Freshwater Molluscs. Cambridge University Press, Cambridge.

Duellman W.E. \& Trueb L. (1986) Biology of Amphibians. McGraw Hill Book Co, New York, NY.

Farlowe V. (1928) Algae of ponds as determined by an examination of intestinal contents of tadpoles. Biological Bulletin, 55, 443-448.

Frost D.R. (2007) Amphibian Species of the World: An Online Reference Version 5.1. American Museum of Natural History, New York. Available at: http://research. amnh.org/herpetology/amphibia/index.php (last accessed on 10 October 2007).

Gosner K.L. (1960) A simplified table for staging anuran embryos and larvae, with notes on identification. Herpetologica, 16, 183-190. 
Grey J., Kelly A., Ward S., Sommerwerk N. \& Jones R.I. (2004) Seasonal changes in the stable isotope values of lake-dwelling chironomid larvae in relation to feeding and life cycle variability. Freshwater Biology, 49, 681-689.

Guelinckx J., Maes J., Driessche P., Geysen B., Dehairs F. \& Ollevier F. (2007) Changes in $\delta^{13} \mathrm{C}$ and $\delta^{15} \mathrm{~N}$ in different tissues of juvenile sand goby Pomatoschistus minutus: a laboratory diet-switch experiment. Marine Ecology Progress Series, 341, 205-215.

Heyer W.R. (1973) Ecological interactions of frog larvae at a seasonal tropical location in Thailand. Journal of Herpetology, 7, 337-361.

Heyer W.R. (1974) Niche measurements of frog larvae from a seasonal tropical location in Thailand. Ecology, 55, 651-656.

Heyer W.R. (1976) Studies in larval amphibian habitat partitioning. Smithsonian Contributions to Zoology, 242, 1-27.

Hillis D.M. \& Wilcox T.P. (2005) Phylogeny of the New World true frogs (Rana). Molecular Phylogenetics and Evolution, 34, 299-314.

Hoff K., Blaustein A.R., McDiarmid R.W. \& Altig R. (1999) Behavior: interactions and their consequences. In: Tadpoles - The Biology of Anuran Larvae (Eds R.W. McDiarmid \& R. Altig ), pp. 215-239. University of Chicago Press, Chicago, IL.

Kupferberg S.J. (1997) The role of larval diet in anuran metamorphosis. American Zoologist, 37, 146-159.

Leibold M.A. \& Wilbur H.M. (1992) Interactions between food-web structure and nutrients on pond organisms. Nature, 360, 341-343.

Menge B.A., Berlow E.L., Blanchette C.A., Navarette S.A. \& Yamada S.B. (1994) The keystone species concept: variation in interaction strength in a rocky intertidal habitat. Ecological Monographs, 64, 249-286.

Moriarty D.J.W. \& Pullin R.S.V. (1987) Detritus and Microbial Ecology in Aquaculture. Conference on Detrital Systems for Aquaculture. International Center for Living Aquatic Resources Management, Bellagio, Como.

Morin P.J. (1983) Predation, competition, and the composition of larval anuran guilds. Ecological Monographs, 53, 119-138.

Petranka J.W. \& Kennedy C.A. (1999) Pond tadpoles with generalized morphology: is it time to reconsider their functional roles in aquatic communities? Oecologia, 120, 621-631.

Polis G.A. \& Winemiller K.O. (1996) Food Webs: Integration of Pattern and Dynamics. Chapman and Hall, New York.

Post D.M. (2002) Using stable isotopes to estimate trophic position: models, methods, and assumptions. Ecology, 83, 703-718.
Rossa-Feres D.C., Jim J. \& Fonseca M.G. (2004) Diets of tadpoles from a temporary pond in southeastern Brazil (Amphibia, Anura). Revista Brasileira de Zoologia, 21, 745-754.

Savage R.M. (1952) Ecological, physiological, and anatomical observations of some species of anuran tadpoles. Proceedings of the Zoological Society of London, 122, 467-514.

Schiesari L.C. (2004) Performance Tradeoffs Across Resource Gradients in Anuran Larvae. PhD Dissertation, The University of Michigan, Ann Arbor, MI.

Schiesari L. (2006) Pond canopy cover: a resource gradient for anuran larvae. Freshwater Biology, 51, 412-423.

Schoener T.W. (1993) On the relative importance of direct versus indirect effects in ecological communities. In: Mutualism and Community Organization: Behavioural, Theoretical, and Food-web Approaches (Eds H. Kawanabe, J.E. Cohen \& K. Iwasaki), pp. 365-411. Oxford University Press, Oxford.

Seale D.B. (1980) Influence of amphibian larvae on primary production, nutrient flux, and competition in a pond ecosystem. Ecology, 61, 1531-1550.

Seale D.B. \& Beckvar N. (1980) The comparative ability of anuran larvae (Genera: Hyla, Bufo and Rana) to ingest suspended blue-green algae. Copeia, 1980, 495503.

Seale D.B. \& Wassersug R.J. (1979) Suspension feeding dynamics of anuran larvae related to their functional morphology. Oecologia, 39, 259-272.

Skelly D.K. (1996) Pond drying, predators, and the distribution of Pseudacris tadpoles. Copeia, 1996, 599605.

Skelly D.K. (2002) Experimental venue and estimation of interaction strength. Ecology, 83, 2097-2101.

Skelly D.K. \& Kiesecker J.M. (2001) Venue and outcome in ecological experiments: manipulations of larval anurans. Oikos, 94, 198-207.

Skelly D.K., Werner E.E. \& Cortwright S.A. (1999) Longterm distributional dynamics of a Michigan amphibian assemblage. Ecology, 80, 2326-2337.

Sterner R.W. \& Elser J.J. (2002) Ecological Stoichiometry: The Biology of Elements From Molecules to the Biosphere. Princeton University Press, Princeton, NJ.

Viertel B. (1982) The oral cavities of central European anuran larvae (Amphibia) morphology, ontogenesis and generic diagnosis. Amphibia-Reptilia, 4, 327-360.

Viertel B. (1990) Suspension feeding of anuran larvae at low concentrations of Chlorella algae (Amphibia, Anura). Oecologia, 85, 167-177.

Wassersug R.J. (1975) The adaptive significance of the tadpole stage with comments on the maintenance of complex life cycles in anurans. American Zoologist, 15, 405-417. 
Wassersug R.J. (1980) Internal oral features of larvae from eight anuran families: functional, systematic, evolutionary, and ecological considerations. Miscellaneous Publications of the Museum of Natural History of the University of Kansas, 68, 1-146.

Werner E.E. (1986) Amphibian metamorphosis: growth rate, predation risk, and the optimal size at transformation. American Naturalist, 128, 319-341.

Werner E.E. (1991) Nonlethal effects of a predator on competitive interactions between two anuran larvae. Ecology, 72, 1709-1720.

Werner E.E. (1994) Ontogenetic scaling of competitive relations: size-dependent effects and responses in two anuran larvae. Ecology, 75, 197-213.

Werner E.E. (1998) Ecological experiments and a research program in community ecology. In: Experimental Ecology: Issues and Perspectives (Eds W.J. Resetarits \& J. Bernardo), pp. 3-26. Oxford University Press, Oxford.

Werner E.E. \& Anholt B.R. (1993) Ecological consequences of the trade-off between growth and mortality rates mediated by foraging activity. American Naturalist, 142, 242-272.

Werner E.E. \& Glennemeier K. (1999) The influence of forest canopy cover on the breeding pond distributions of several amphibian species. Copeia, 1, 1-12.

Werner E.E. \& McPeek M.A. (1994) Direct and indirect effects of predators on two anuran species along an environmental gradient. Ecology, 75, 1368 -1382.

Wilbur H.M. (1997) Experimental ecology of food webs: complex systems in temporary ponds. Ecology, 78, 2279-2302.
Wilbur H.M. \& Alford R.A. (1985) Priority effects in experimental pond communities: responses of Hyla to Bufo and Rana. Ecology, 66, 1106-1114.

Woodward B.D. (1982) Tadpole competition in a desert anuran community. Oecologia, 54, 96-100.

Yurewicz K.L. (2002) Size Structure and Intraguild Interactions in Larval Salamanders. PhD Dissertation, The University of Michigan, Ann Arbor, MI.

\section{Supporting Information}

Additional Supporting Information may be found in the online version of this article:

Appendix S1. Isotopic composition and foregut content C:N (by mass; mean $+\mathrm{SE}$ ) of enclosed- and free-ranging anuran larvae in the study ponds.

Appendix S2. Diet of free-ranging anuran larvae as indicated by a qualitative gut content analysis under $<50 \times$ magnification.

Please note: Wiley-Blackwell are not responsible for the content or functionality of any supporting materials supplied by the authors. Any queries (other than missing material) should be directed to the corresponding author for the article.

(Manuscript accepted 24 September 2008) 